\title{
Reenacting the '90s Romanian Advertising: From the Revelation of Delights to the Ascent of GSM
}

\author{
Călin CRAINIC, PhD \\ Department of Communication, Public Relations, and Advertising \\ Faculty of Political, Administrative and Communication Sciences \\ Babeș-Bolyai University, Cluj-Napoca, Romania \\ E-mail: calin.crainic@kumpania.ro
}

\begin{abstract}
Creativity research is a field still open to many types of exploration. The need for accurate instruments led researchers to various attempts during different periods. The present paper proposes a plunge back into the Romanian '90s when advertising was in its infancy. With a content analysis proposed and experts' interviews, the research digs into a couple of aspects that defined the socially and economically tormented Romanian transition. The major concepts used in the paper are the divergencerelevance pair for assessing the general frames of creativity, as well as the systematic inventive thinking for identifying creative patterns. The focus is on identifying the major themes of that period, coupled with opinions obtained from creative experts who worked in advertising in those years.
\end{abstract}

Keywords: Divergence; Relevance; Systematic inventive thinking; Press advertisements; '90s Romania. 


\section{Introduction}

Setting the course for creativity research brings forth several challenges. As it was often mentioned in the literature, the major predicament is constructing a set of valid measurements. This should offer deep insights into how creativity is reproduced into an ad and what is its intrinsic value. Thus, the following pages are dedicated to presenting the major trends identified in the "90s Romanian press advertising, by analyzing press ads from the whole period. The analysis is detailed based on several themes that dominated the market landscape at that time. And which were drawn from the analysis of the press ads. Furthermore, the content analysis is doubled and sustained by responses gathered from creative specialists who worked in advertising during the ' 90 s, through interviews.

The fundamentals of the content analysis were defined based on the divergencerelevance dichotomy in the literature (Goldschmidt, 2016), as well as the Systematic Inventive Thinking (SIT) model (Goldenberg, Levav, Mazursky, \& Solomon, 2009), meant to fill in a couple of conceptual voids. Thus, the paper looks at some general introductory aspects of creativity, followed by the operationalization of divergence and relevance, as well as the main SIT instruments. These are the main theoretical concepts on which the content analysis and the interviews were built. The results are part of a more complex research. The total amount of advertisements selected for the paper was 700 . The major trends identified were coupled with a couple of ideas from the experts' interviews.

The main points of interest of this paper are tuned to the following research questions:

Q1. Which of the two pillars of creativity - divergence and relevance - is most representative for the product categories in the '90s print advertisements?

Q2. What are the major highlights of that period in terms of communication initiatives?

And a hypothesis which sustained the quantitative endeavor:

H1. The new category entries (GSM, copy \& print, computers) are a positive predictor for the divergence level.

\section{Theoretical framework}

The first concept put under the lenses is divergence. As suggested in the literature, it enables the inquiry of several alternatives. It eludes the rational and straightforward thought processes which lead to rational solutions. It embraces artistry, intuition, and encourages emotional articulation (Moriarty, Mitchell, \& Wells, 2011, 247). The authors who supported this concept in various research circumstances, propose various sets of factors for its measurement. However, given the similitude of meanings between them, we propose comprising them 
into three major concepts which could be considered the roots of divergence. The first is the innovation which gathers all the unexpected and original elements of an advertisement. The second factor, flexibility, leads it one step further and underlines the importance of variation among ideas, as well as their capacity of shifting from one angle to another. The third one, elaboration, suggests adding depth to the ideas at hand, extending their meaning and also adding a touch of sophistication (Lehnert, 2010, 10).

It is well known that advertisements which outstanding features lead the consumer's attention. These are the ones capable of bearing complex messages (Shirkhodaee \& Rezaee, 2014, 591). Nevertheless, the biggest challenge remains not so much conceived unparalleled scenarios, as finding the ideas which tackle the communication process in an original manner (Moriarty et al., 2011, 231). As divergence puts into the spotlight the most unusual ideas, it is often mistaken or equated to divergence. Still, many authors believe it is but a small part and that the number of studies was extremely low in the past decades (Smith, MacKenzie, Yang, Buchholz, \& Darley, 2007, 820).

Another important aspect to be remembered is that communication experts and consumers have disparate perceptions regarding creativity. However, previous studies indicate that the two groups have similar opinions regarding its dimensions (Modig \& Dahlen, 2019, 3). This enabled us to consider the items revealed by the literature as having a holistic nature for the analysis. The approaches regarding this topic have met various split ends. Some researches focused on grasping the concept of advertising in its entirety, while others focused on defining creative styles. All these have a common thread: they all relied on the consumers' perception, placing the accountability on their opinions (Mercanti-Guérin, 2008, 98).

What should be kept in mind is that creative executions come with a sensible amount of responsibility. The general perception among consumers is that a highly creative execution comes as a promise of a high-quality product. The same idea was backed by previous researches in terms of spending a generous amount on advertisements. The more imposing an advertisement is, the more it suggests the idea that the brand has consistent resources that enable it to deliver good products or services (Dahlen, Rosengren, \& Karsberg, 2018, 1).

The relevance is understood as the attempt of strategically tuning to the market and the consumer. Although creativity implies innovative and unusual measures, it is a strategically oriented undertaking. This is the starting point of comprehending relevance. Unfortunately, few studies addressed this concept and its underlying issues (Sasser \& Koslow, 2012, 202). Those who reinforce it suggest that the innovative aspects of an advertisement are not enough, as the execution should carry purposeful notions regarding the product. The relevance is meant to complete the innovative aspects, redirecting the creative tools towards the consumers' resources for solving his needs (Modig \& Dahlen, 2019, 3). 
The relevance focuses on the meaning, the appropriateness of the product and its value for the target group. It is emulated through elements that bring added significance to the execution (Smith \& Yang, 2004, 36). It is formed from objective pieces of information, as the added inspiration and transformation are conceived by the copywriter and the art director. It is an indispensable element of an advertisement, without it, the whole creative effort being useless (Drewniany \& Jewler, 2008, 27).

As in the case of divergence, there are several factors thought to compose this concept. After bridging their meanings, there are three which stood out. The first is the appropriateness. This criterion ensures that the advertisement is adapted to the social and economic context. The second is connectedness, which ensures an overview of the consumers' expectations regarding a certain product or service. And the third one is comprehension, reflecting not only a deep understanding of the consumers' aspirations, but also his needs (Lehnert, Till, \& Ospina, 2014).

The systematic inventive thinking is a subset of eight patterns, which bring forth recurrent creative ideas collected after years of research. These were obtained after analyzing several years many prized advertising executions (Tevi, Koslow, \& Parker, 2018, 6). As the literature suggests, using these patterns does not undermine the creative efforts. Quite the opposite, they proved efficient in various contexts and under various purposes, and proved to stir profound meanings in the mind of the consumer (Goldenberg et al., 2009, 9). It was a sign that unconventional tactics can be also educated and redirected toward finding creative solutions (Ansburg \& Dominowski, 2000, 31).

The SIT instruments have been split into two categories. The first one embodies the unifying tactics: unification, activation, metaphor and subtraction. These are the tactics strongly linked to the media environment and make use of all its resources to convey a message. The other four are part of the extreme tactics: extreme consequence, absurd alternative, inversion, and extreme effort. These are the ones that focus on the message before anything else and add an extreme touch to the manner of advertising it (Goldenberg et al., 2009, 14).

\section{Methodology}

There are three focal points of the analysis. The first is divergence, coupled with relevance, and the SIT instruments which serve as a backing instrument, providing the frames through which the ads can be categorized. As it was underlined in the introductory section, the first research method employed was the content analysis. The main reason for using it resides in the method's capacity of setting valid and reusable factors, starting from a given set of data and a context (Krippendorff, 2004). The instrument linked concepts such as divergence and relevance to pressing advertisements from the daily Adevărul and the daily România Liberă, from 1993 to 1999. These were the newspapers with the highest circulation in the chosen period. 
The reason for eliminating 1990, 1991, and 1992 is strongly connected to the fact that the promotional materials had the structure of an announcement, not an advertisement. The sample consists of 700 print advertisements (Table 1). There were 100 advertisements chosen for each year of the analyzed period, to identify the underlying themes which dominated it.

Moreover, for a better structure of the content analysis, all the advertisements were split into product/ service categories. However, there are only a couple of categories that will be of interest for this research: GSM, Automotive, Computers, Copy/ Print, Home appliances, Financial, Alimentary, Non-alcoholic beverages, HORECA. The new entries in terms of categories are computers, copy/ print, and GSM. The most desired categories were home appliances, audio-video equipment, automotive, alcoholic beverages, and non-alcoholic beverages.

The content analysis comprised 16 items, each split according to four major sections: Innovation, Flexibility, and Elaboration for divergence, and Appropriateness \& Connectedness for relevance. In the case of innovation- which is the strongest indicator for divergence- there were SIT instruments inserted among the factors. The coding was dichotomous, indicating where each item was present.

For a better grasping of the concepts used, we will shortly review each major section. The first one is Innovation (Table 1). It comprised three sections, aiming at defining individual aspects concerning the text and the image, as well as the combination resulted from the two - image \& text.

Table 1. Innovation

\begin{tabular}{|c|c|c|}
\hline \multicolumn{3}{|c|}{ Innovation } \\
\hline \multirow{9}{*}{$\begin{array}{l}\text { The factor which measures creativity based } \\
\text { on originality, novelty, and surprise } \\
\text { (the surprise element of an advertisement) }\end{array}$} & \multirow{3}{*}{ Text } & Polysemy \\
\hline & & Wordplay \\
\hline & & Typography \\
\hline & Image & Metaphor (SIT) \\
\hline & \multirow{5}{*}{ Text \& Image } & Visual polysemy \\
\hline & & Extreme consequence (SIT) \\
\hline & & Absurd alternative (SIT) \\
\hline & & Extreme effort (SIT) \\
\hline & & Activation (SIT) \\
\hline
\end{tabular}

As previously mentioned, the innovation section also comprised SIT instruments. From the total set of eight, five were used in the analysis. Two were selected from the unifying family: the metaphor and activation.

- The metaphor uses a visually innovative message. It either combines two benefits that should be promoted, or it combines the image of the product with one of these benefits. On many occasions this is done in an abstract manner.

- The activation is inviting the consumer to take any action through the combination of text and image. 
The other three instruments were chosen from the extreme family: extreme consequence, absurd alternative, and extreme effort.

- The extreme consequence presumes to exaggerate the benefit of a product or a service, to make it stand out. It employs the "It's so.... that" formula.

- The absurd alternative illustrates an irrational alternative of replacing the product. The key idea is envisioning how the world would look without the product/ service.

- The extreme effort bridges the image and the text into the effort someone would make for acquiring a certain product. The principle is doing everything in one's power to get it.

The second pillar of divergence is Flexibility (Table 2). As in the case of innovation, the concept is split into the same three items: text, image, text \& image. Its core-specific is changing the perspective through one of the items.

Table 2. Flexibility

\begin{tabular}{|c|c|c|}
\hline \multicolumn{3}{|c|}{ Flexibility } \\
\hline \multirow{3}{*}{$\begin{array}{l}\text { Ensuring the semantic frame } \\
\text { for innovation. It is characterized } \\
\text { by the change of perspective. }\end{array}$} & Text & Perspective change at the textual level \\
\hline & Image & Perspective change at the visual level \\
\hline & Text \& Image & Changing the visual perspective using the text \\
\hline
\end{tabular}

The third concept and the one which complements divergence is Elaboration (Table 3). Opposed to the other two sections, it focuses on only two aspects: the clarity and depth of the promoted idea and the benefit. It heavily relies on the visual aspects of the advertisement.

Table 3. Elaboration

\begin{tabular}{ll}
\hline \multicolumn{1}{c}{ Elaboration } & \\
\hline $\begin{array}{l}\text { Clarity of the core idea, rendered through graphic design, } \\
\begin{array}{l}\text { as well as the distribution of the elements of the press ad: } \\
\text { headline, baseline, body copy, logo }\end{array}\end{array}$ & $\begin{array}{l}\text { Clarity of the benefit } \\
\text { of the product/ service }\end{array}$ \\
\hline
\end{tabular}

The last section belongs to aspects regarding Relevance (Table 4). The two main items which compose the instrument are appropriateness and connectedness. These reflect best the comprehension of the consumers' desires and needs.

Table 4. Appropriateness \& Connectedness

\begin{tabular}{ll}
\hline \multicolumn{1}{c}{ Appropriateness \& Connectedness } \\
\hline Appropriateness & $\begin{array}{l}\text { The press ad has elements that reveal the appropriateness, based on the target } \\
\text { group's needs. These elements can be implied (the notoriety of a certain brand) or } \\
\text { explicit (elements which reflect the consumption need or opportunity) }\end{array}$ \\
Connectedness & $\begin{array}{l}\text { The press advertisement promotes the product or the brand as being of public usage } \\
\text { (business to business or business to consumer) }\end{array}$ \\
\hline
\end{tabular}


The expert interview will be employed as a support for the findings in the content analysis sections and will provide in-depth insights regarding the identified issues. Part of the interview guide was dedicated to each of the categories, overviewed through the content analysis grid.

The research questions are:

Q1. Which of the two pillars of creativity - divergence and relevance - is most representative of the product categories in the ' 90 s print advertisements?

Q2. What are the major highlights of that period in terms of communication initiatives?

And the hypothesis:

H1. The new category entries (GSM, copy \& print, computers) are a positive predictor for the divergence level.

\section{Recurrent themes}

\section{A. The revelation of delights}

The press ads from the HORECA, tobacco, or non-alcoholic beverages did not stand out in the general landscape. The most representative for these categories is the alimentary category, which included everyday consumer goods. All the ads from the three sections had relevant markers, having the connectedness trait present through the textual and visual cues. The existence of many alimentary products is sustained by the scarcity from the previous totalitarian era. The desire of consumption was at such high levels, that communicators did not consider necessary to include cues dedicated to appropriateness, for instance. The selling was self-generated.

However, the divergent aspects cannot be left aside. It is important to note the categories, as well as the products. A leader in divergence for the non-alcoholic beverages is Coca-Cola. Still, local examples, such as the "Excelent" chocolate bars are also worth mentioning.

The experts added to these ideas. The most prominent appearance in terms of alimentary products was the Turkish brand Ülker: "It was flooding of Turkish companies on the market which, overall, were huge investors. Ulker, for instance was one of the big advertisers. [...] I recall their attempts of showing their greatness and promoting all their products on the buses"(Ș.A.). The local executions were considered to be asynchronous, relating them to the international landscape: "Generally speaking, everything was conceived based on the slice-of-life principle. The type of advertising which was left behind by the USA 10-15 years before that era"(S.T.).

Also, the beverages leaders that emerged were Coca-Cola and Pepsi: "The two major players, Pepsi and Coca-Cola, took their first communication steps by bringing foreign commercials" (S.P.). The international brands standardized their first campaigns, having small initiatives in terms of getting accustomed to local needs. 


\section{B. The burst of home appliances}

The same relevant trend was maintained, just like in the case of the previous categories. The main focus was revealing the product as a novelty, its appearance being treated like an event. Because they were initially perceived as belonging to the luxury category, the most accessible strategies were the promotions. The appropriateness was not as well-rounded because of the product nature. Being dedicated to a large pool of customers by default, these aspects were not among the communicational priorities.

NEI and Goldstar were the two ubiquitous brands. The messages were extremely low in terms of creativity because consumers were avidly searching for products such as TVs. Seemingly, the same phenomenon of exacerbated consumption could be found everywhere. This is also what the experts state: "There are a couple of star brands from the transition: NEI, Goldstar, the bubble washing machine from Daewoo" (F.D.). They also underlined the lack of creative appeal: "As far as I can remember, there was not much of a "creative verve". The main attention points were the diagonals, the prices, again diagonals... Still, this does not mean that there were not a lot of noise in this category. The Romanian consumer filled his home with everything he lacked until then.” (S.A.). It was the era of the naïve consumer and the raw interactions between him and the brands.

\section{Financial services and the quest for easy money}

This was a brand-new category for ' 90 s Romania. Unlike the other categories, the press advertisements revealed that it slowly entered the market. As the economic measures started to change, the Romanian consumers began searching for investing services. The mirage of quick money rapidly took by storm the unprepared consumers. The fall of pyramidal money games produced a deep mistrust between consumers and the banks. Nevertheless, a significant proportion of the ads indicated that the communicational efforts were consistent for this segment.

This was also "translated" into higher creative efforts. Unlike the previous categories, the innovation was present in a greater amount. There were many more visual polysemies than in other categories. In contrast with the previous ones, there were considerably more efforts put into directing the message. The experts revealed the constant efforts of the banks to promote messages of trust: "In the '90s, the banks and the insurance companies were interested to promote a single type of message: of security, trust, and stability. There were campaigns filled with powerful, impressive symbols"(F.D.).

It was a typology used in almost all of the financial advertisements. The man in the costume who must exude seriousness and must raise the credibility level of the initiatives which were shaking: "The campaigns from this category (n.r. financial services) were summed up to revealing somber people, in impeccable costumes, who seemed to know very well what they were doing " (S.P.). 


\section{Automotive fascination}

Similar to the case of the home appliances, the automotive industry also had a major impact on the Romanian consumer. Being freed of all the years of waiting for acquiring a car, followed by never-ending lines for gas refills, the consumers quickly fell for the newcomer Daewoo brand. This was one of the early signs of the internationalization of the market. The press advertisements were conceived around promoting cars and components. While there were some international new entries, the local Dacia still tried to promote itself by making appeals to price and nostalgia.

Notwithstanding, Dacia was still promoting moderate behavior, inviting consumers to be sober-minded. An attitude which, as the press advertisements reveal, was extremely appreciated back in those days: "The best car is the care that you can afford" (headline). Coupled with this, there was also an appeal to the "civilized commerce" in the jungle of supply and demand.

The resemblance to the home appliance category is also sustained by the experts: "They are quite the same. A reason for which I could not specify brands or specific commercials"(C.T.). After years of perpetuating an empty language, the creatives were finally put in the situation of breaking the norms. Still, there were a lot of obstacles to be surpassed: "We were working for Daewoo back then. The communication process was quite toilsome. The Koreans from the marketing department were talking a very special form of English. We were struggling, but there are also many funny memories and stories which now would seem invented"(A. G.).

\section{E. The miracle of the printing machines}

This category has developed in parallel with the IT industry. Using these components was specially destined for the business medium. Thus, market positioning has considered some norms. Being a category that did not have the dissonance between appropriateness and connectedness, it managed to invest more consistently in the brand awareness area. A major representative is Xerox. It was uncanny the campaign through which they set the objective of explaining which is the difference between a copy and xerox.

It is one of the first categories to have a major presence in terms of divergence. There is not the case for press advertisements without relevance, but this is one of the main domains where creativity could finally be noticed.

Interestingly, the experts could not reproduce many examples, stating that, for them, the creative aspects could not be so noticeable: "No, I am terribly sorry, I cannot remember anything. Except the Minolta people" (A.P.). Some other experts recalled working for Xerox and labeled the period as having "clean" messages. This did not indicate a definitive raise in the creativity levels: "I was working for Xerox. I do not remember the campaign- everything was for print and with a small budget- but I do remember how funny it was that the whole market was "xeroxing"(A.G.) 


\section{F. The ascent of GSM}

The year 1997 was the one that dramatically changed the print landscape. It was the year of the launch of two major GSM operators: Connex and Dialog. The GSM advertisement was the most consistent not only for this year but for the other two years which followed in the analysis. It was rich in divergent cues, not only in terms of messages, but also regarding the media placement and the strategic and creative communication efforts.

Each entry on the market for the two giants was marked by a teasing campaign. The press advertisement could obtain high innovation scores only by visually manipulating the text. It was, by far, the category with the largest amount of divergent materials. Moreover, in the case of GSM, there is a stronger preoccupation for appropriateness and exact targeting.

Even the experts point out that the GSM category was clearly distinct from all the other categories and all other communicational initiatives: "I believe the launching campaign of the GSM services was highly significant. It was the answer to huge needs and it reached its target with maximum precision"(E.P.) It was suggested the fact that the whole period could somewhat be divided in the "before and after" of the GSM appearance: "The GSM had, without a doubt the best products, the most ambitious and modern Romanian advertisements" (S..A.). And, besides the products and services, it was bringing, it was also the turning point for the Romanian advertising as a whole: "The entrance on the local market for the telecom players was an important moment for the advertising industry, also, as the budgets grew considerably and the clients' requests likewise”(S.P.).

\section{Discussions and conclusion}

The Romanian '90s were marked by social and economic changes and disturbances which were reflected in the advertisements of that period. Regarding the first research question:

Q1. Which of the two pillars of creativity - divergence and relevance - is most representative of the product categories in the '90s print advertisements?

The answer actually splits the time frame. The first years of the analyses 19931996 were dominated by relevance. The majority of the categories had executions that could easily be placed in the relevant section. However, the last three years, 1997-1999, were effervescent and full of divergent executions. This was due to the appearance of the GSM services which reshaped the entire advertising landscape.

Q2. What are the major highlights of that period in terms of communication initiatives?

The major highlights are the international entries on the local market in all of the categories. The consumers were marked by the fever of buying without restriction, 
finally filling their homes with the products they could only dream of during the previous regime. The second highlight of the analyzed period was the appearance of the GSM operators. They managed to impose change not only at a societal level but also in terms of advertising endeavors and communication gestures.

Finally, the hypothesis "The new category entries (GSM, copy \& print, computers) are a positive predictor for the divergence level" was validated. The new categories have been, in fact, the ones which determined change in all life sectors. These were the ones that not only brought progress in terms of technological aspects, but they also forced a change in terms of communicating and understanding the consumers' needs and desires. As well as they brought significant lessons in terms of appropriate messages for target audiences.

\section{Limits and future perspectives}

The first limit is the few analysis factors used in the present paper. For deeper insights, a more detailed quantitative analysis has to be performed. Furthermore, these results should be associated in-depth with the whole interview guide and deeper experiences of the professionals who worked in those years.

Another limitation is linked to the character of novelty for the content analysis. There would be more replications necessary to reveal its applicability in various creative advertising contexts.

\section{References}

1. Ansburg, P. I., \& Dominowski, R. L. (2000). Promoting Insightful Problem Solving. fournal of Creative Behavior, 34(1), 30-60.

2. Dahlen, M., Rosengren, S., \& Karsberg, J. (2018). The Effects of Signaling Monetary and Creative Effort in Ads Advertising Effort Can Go a Long Way Influencing B2B Clients, Employees, and Investors. fournal of Advertising Research, 59(4), 1-10. https://doi.org/1 0.2501/JAR-2018-013.

3. Drewniany, B. L., \& Jewler, A. J. (2008). Creative Strategy in Advertising (11th Edition). Boston: Thomson Wadsworth.

4. Goldenberg, J., Levav, A., Mazursky, D., \& Solomon, S. (2009). Cracking the Ad Code. Cambridge: Cambridge University Press.

5. Goldschmidt, G. (2016). Linkographic Evidence for Concurrent Divergent and Convergent Thinking in Creative Design. Creativity Research fournal, 28(2), 115-122. https://doi.org/1 0.1080/10400419.2016.1162497.

6. Krippendorff, K. (2004). Content Analysis. An Introduction to Its Methodology. Sage Publications.

7. Lehnert, K. (2010). Investigating creativity's effectiveness: A multi-method approach. Saint Louis University. 
8. Lehnert, K., Till, B. D., \& Ospina, J. M. (2014). Advertising Creativity: The Role of Divergence versus Meaningfulness. Journal of Advertising, 43(3), 274-285. https://doi.org /10.1080/00913367.2013.851630.

9. Mercanti-Guérin, M. (2008). Consumers' perception of the creativity of advertisements: development of a valid measurement scale. Recherche et Applications en Marketing, 23(4), 97-118. https://doi.org/10.1177/205157070802300405.

10. Modig, E., \& Dahlen, M. (2019). Quantifying the Advertising-Creativity Assessments of Consumers Versus Advertising Professionals. Does It Matter Whom You Ask? Journal of Advertising Research, 1-14. https://doi.org/10.2501/JAR-2019-009.

11. Moriarty, S., Mitchell, N., \& Wells, W. (2011). Advertising \& IMC. Principles \& Practice (Ninth Edit). New Jersey: Pearson Education.

12. Sasser, S. L., \& Koslow, S. (2012). Creativity and Ad Theory. In S. Rodgers \& E. Thorson (Ed.), Advertising theory (pp. 191-211). New York: Routledge.

13. Shirkhodaee, M., \& Rezaee, S. (2014). The Power of Creative Advertising and Consumers' Perceived Risk. Journal of Promotion Management, 20(5), 590-606. https://doi.org/10.108 0/10496491.2014.946209.

14. Smith, R. E., MacKenzie, S. B., Yang, X., Buchholz, L. M., \& Darley, W. K. (2007). Modeling the Determinants and Effects of Creativity in Advertising. Marketing Science, 26(6), 819833. https://doi.org/10.1287/mksc.1070.0272.

15. Smith, R. E., \& Yang, X. (2004). Toward a general theory of creativity in advertising: Examining the role of divergence. Marketing Theory, 4(1/2), 31-58. https://doi.org/10.117 7/1470593104044086.

16. Tevi, A., Koslow, S., \& Parker, J. (2018). Can Media Neutrality Limit Creative Potential? How Advertising's Use of Ideation Templates Fares across Media. Fournal of Advertising Research, 59(3), 1-17. https://doi.org/10.2501/JAR-2018-040. 